\title{
Implementation of quantitative bushfire risk analysis in a GIS environment
}

\author{
Dale Atkinson $^{\mathrm{A}}$, Mark Chladil $^{\mathrm{B}}$, Volker Janssen ${ }^{\mathrm{A}, \mathrm{C}}$ and Arko Lucieer $^{\mathrm{A}}$ \\ ${ }^{\text {A }}$ School of Geography and Environmental Studies, University of Tasmania, \\ Private Bag 76, Hobart TAS 7001, Australia \\ ${ }^{\mathrm{B}}$ Tasmania Fire Service, GPO Box 1526, Hobart TAS 7000, Australia \\ ${ }^{\mathrm{C}}$ Corresponding author. Email: Volker.Janssen@utas.edu.au
}

\begin{abstract}
Bushfires pose a significant threat to lives and property. Fire management authorities aim to minimise this threat by employing risk management procedures. This paper proposes a process of implementing, in a Geographic Information System environment, contemporary integrated approaches to bushfire risk analysis that incorporate the dynamic effects of bushfires. The system is illustrated with a case study combining ignition, fire behaviour and fire propagation models with climate, fuel, terrain, historical ignition and asset data from Hobart, Tasmania, and its surroundings. Many of the implementation issues involved with dynamic risk modelling are resolved, such as increasing processing efficiency and quantifying probabilities using historical data. A raster-based, risk-specific bushfire simulation system is created, using a new, efficient approach to model fire spread and a spatiotemporal algorithm to estimate spread probabilities. We define a method for modelling ignition probabilities using representative conditions in order to manage large fire weather datasets. Validation of the case study shows that the system can be used efficiently to produce a realistic output in order to assess the risk posed by bushfire. The model has the potential to be used as a reliable near-real-time tool for assisting fire management decision making.
\end{abstract}

Additional keywords: bushfire simulation, fire behaviour, fire probabilities, modelling, Tasmania, wildfire threat analysis.

\section{Introduction}

Bushfires in Australia are significant threats to lives and property. Examples of the destructive nature of bushfires are the disastrous Hobart fires of 1967, the Ash Wednesday fires throughout Victoria and South Australia in 1983, the Canberra fires of 2003 and, most recently, the Victorian fires in 2009 (the worst natural disaster in Australia's history). Bushfires exhibit spatial and temporal patterns of occurrence and resulting damage. Spatially variable factors such as slope, aspect, ignition patterns, fuel characteristics and fire weather all contribute to the overall threat posed by bushfire (e.g. Luke and McArthur 1978; Tolhurst and Cheney 1999; Bradstock and Gill 2001; Genton et al. 2006).

Fire management authorities aim to minimise threat through a range of strategies, such as fuelreduction burns, resource allocation and community education. In order to implement these strategies effectively, a risk-management process is employed. The bushfire risk analysis process is an important part of this strategy as it aims to not only determine the spatial extent of the risk but also quantify the risk, such that fire managers can make informed decisions whether to accept or treat the risk. As improvements in data quality and technology arise, risk-related questions become more complex and multi-faceted; thus, the bushfire risk analysis process is evolving. For example, fire managers are increasingly pushing for spatiotemporal information to be available in near-real-time.

Shields and Tolhurst (2003) introduced a contemporary integrated approach to bushfire risk analysis, incorporating the dynamic effects of bushfires. Our study develops a method of implementing this approach using currently available data. A case study for the greater Hobart area, Tasmania, is provided using ignition, fire behaviour and fire propagation models along with climate, fuel, terrain, historical ignition and asset data in a Geographic Information System (GIS) environment.

There are two main approaches to fire spread modelling, categorised as those linked to a regular grid (raster-based) and those linked to a continuous plane (vector-based). In raster-based models, each whole cell is represented as burnt, burning or unburnt (Berjak and Hearne 2002). Vector-based models are often based on Huygens' principle, which states that wave fronts can be propagated from discrete points acting independently, and involve representing a fire front for different terrain and wind conditions using a series of ellipses (Knight and Coleman 1993; Finney 2002). 
This paper proposes a process of implementing a quantitative method of raster-based bushfire risk analysis. The presented procedure is not limited to the chosen dataset and may be applied incorporating many other parameters and models for other locations.

\section{Previous bushfire risk studies}

Bushfire risk analysis (also known as wildfire threat analysis) methods produced during the mid- to late 1990s were generally qualitative or semiqualitative in nature and used components such as hazards, ignition risks and values. The hazard layer included estimates of fuel load based on vegetation, land cover and fire history and used standard weather and fuel predictions to generate fire front intensities for each raster cell. Other layers involved buffers from civil infrastructure as an ignition risk and a values layer of natural and constructed assets (Malcolm et al. 1995; NZ NRFA 2005). Hazard and risk of ignition measures were put into a risk analysis matrix and given a value of high, medium or low. Then the high-risk hazard was overlaid with the values layer to determine the areas that were most at risk. Examples of this approach were presented by Malcolm et al. (1995), Garvey (1996), Smith (1998) and Jones et al. (2004).

The Wilson (1998) report (cited in Shields 2004) invoked a whole new range of thinking as to the usefulness of the wildfire threat analysis. Wilson suggested that there were many shortcomings in the established techniques and that they could mislead fire managers. He based this on two points:

1. The relationship between layers in bushfire risk management is not simply arithmetic, e.g. a fire ignition at one point in an area could interrelate with fuel and assets over a much wider area. The approach taken in wildfire threat analysis did not have the flexibility to deal with dynamic effects.

2. Threat as a single output was of little use in guiding fire managers.

\section{Quantitative and statistical approaches}

The purpose of a quantitative approach is to not only recognise the areas most at risk but to produce a realistic estimation of the actual magnitude of the risk posed.

Preisler et al. (2004) produced a method for quantitative analysis based on conditional probabilities of a fire firstly occurring and then becoming large. Bradstock and Gill (2001) also produced a statistical method, quantifying the risk posed by bushfires to people as a function of a chain of linked probabilities of occurrence:

$$
D=I \cdot S \cdot E \cdot G \cdot H
$$

where $D$ is the adverse risk to humans and property, $I$ is the probability of ignition in the landscape, $S$ is the probability of fire reaching the urban interface, $E$ is the probability of fire encroaching into the built environment, $G$ is the probability of fire propagating within the built environment, and $H$ is the probability of fire propagating within buildings.

The framework developed by Shields and Tolhurst (2003) for quantifying the risk posed by bushfire addresses the problem of including the dynamic effects of bushfire. This is achieved by including a fire propagation model to estimate the probability of an ignition in the landscape reaching the urban interface. By repeating this procedure for thousands of possible ignitions and varying fire weather scenarios, the likelihood of a fire reaching each urban interface point can be determined. Based on this likelihood, risk measures can then be obtained.

\section{Defining risk measures}

Risk is defined as 'the chance of something happening that will have an impact on objectives' and assessed in terms of likelihood and consequences (AS/NZS 2004):

$$
\text { risk }=\text { likelihood } \cdot \text { consequence }
$$

Applying this to bushfires, the likelihood component is the probability of a fire start (ignition) and spread (growth) and the consequence component is the impact of this fire starting and spreading.

This study concentrates on fires reaching and encroaching into the built environment. As such, the first three terms in Bradstock and Gill's (2001) equation (Eqn. 1) are used to determine the likelihood of a fire reaching and encroaching into the built environment: 
where $P_{i}$ is the probability of ignition, and $P_{s}$ is the probability of spread (based on the probability of fire-promoting weather conditions and the probability that on the given day the ignition will spread to the urban interface). $P_{e}$ is the probability of the fire encroaching into the built environment, i.e. the probability that the fire will spot into the built environment based on fireline intensity at the interface and wind direction. The consequence component from Eqn. 2 is dealt with later in this paper.

\section{Study area}

The study area covers approximately 50,000 ha in the greater Hobart area of Tasmania, Australia. This area has a population of approximately 200,000 and ranges in elevation from sea level to $1270 \mathrm{~m}$ at the summit of Mt Wellington. Analysis of the Tasmanian Vegetation Map (TASVEG) dataset for 2005 (TVMP 2005) revealed that approximately $21 \%$ of the study area is urban or non-vegetated and $20 \%$ agricultural or native grassland. The remainder consists of approximately $85 \%$ dry eucalypt forest, $7 \%$ wet eucalypt forest and $8 \%$ scrubland, together with heathland, moorland, wetland and non-eucalypt forest.

\section{Deriving an estimate of the probability of ignition}

Tasmania Fire Service incident data were examined for the 7-year period between 1 July 1998 and 30 June 2005. The data consisted of 8416 vegetation fires that occurred during this time period. Although the time period of 7 years is not a large enough temporal window to determine a fully reliable ignition layer, the significant number of ignitions allowed the generation of an ignition estimate deemed sufficient for this study. Information included the date, time, street and suburb of the initial call-out. Post-incident information included type of incident (grassfire, scrubfire, etc.), form of ignition (e.g. match, discarded cigarette, welding sparks) and a six-figure grid reference. Although this dataset contained only the ignitions that were severe enough for the fire service to attend, it was assumed to be representative of all ignitions that occurred during the period.

Analysis of the form of ignition showed that natural causes (e.g. lightning and spontaneous combustion) contributed to less than $0.1 \%$ of the total incidents recorded over this time period. As most ignitions resulted from human activity, human accessibility in the study area was investigated, quantified by a factor based on the distance from the nearest road $(d R)$. This rather simple ignition model is deemed sufficient owing to the meteorological conditions and the type of ignitions experienced in the study area. It is recognised that natural causes would need to be investigated more thoroughly in most other areas. The use of digital elevation model (DEM) derivatives such as plateaus, ridge-tops and exposed slopes can be very useful in this regard because lightning ignitions tend to occur in these areas (McRae 1992).

Generally, buffers from roads are used to model the probability of ignition in relation to human accessibility (Malcom et al. 1995; NZ NRFA 2005). In the present study, the distance relationship was examined based on historical incident data. This procedure involved: (1) calculating the distance from each ignition point to the nearest road; (2) converting all possible grid references to a point layer; (3) calculating the distance from all possible grid references to the nearest road; and (4) binning the distance values into $10-\mathrm{m}$ intervals.

The cumulative percentage of both the ignition dataset and all possible grid references was calculated based on the distance to the nearest road. Using all possible grid references, an expected percentage of data per distance from the road could be calculated. The relationship was analysed using a similar method to the L-function for cluster analysis (Ripley 1976), and it was found that the number of ignitions within $200 \mathrm{~m}$ of roads is equivalent to the expected number within $1542 \mathrm{~m}$ if the data were completely random. Hence, significant clustering around roads exists in the data (Genton et al. 2006).

About $94 \%$ of ignition points were within $100 \mathrm{~m}$ of a road and over $99 \%$ were within $200 \mathrm{~m}$. As the ignition data accuracy was of the order $\pm 50 \mathrm{~m}$, the relationship was quantified for 50 -m distance intervals $(d R)$ (Table 1$)$. 
Table 1. Probability estimate that an ignition will occur for distance-from-road $(d R)$ intervals, derived from observed frequencies of historical data

\begin{tabular}{cc}
\hline$d R(\mathrm{~m})$ & Probability $\left(P_{d}\right)$ \\
\hline $0-50$ & 0.780 \\
$50-100$ & 0.160 \\
$100-150$ & 0.050 \\
$150-200$ & 0.001 \\
$>200$ & 0.001 \\
\hline
\end{tabular}

Thus, for incidents with a street reference only, the data could be plotted spatially using Table 1 . Roads were stratified into three categories (i.e. road class) based on natural breaks in the ignition density $(I D)$ given by:

$$
I D=\frac{N_{r}}{L_{r}}
$$

where $N_{r}$ and $L_{r}$ indicate the number of ignitions referenced to the road and the total length of the road respectively.

Therefore each cell can be given a probability of ignition $\left(P_{i}\right)$ for a given fire season based on road class and distance (adapted from Shields 2004):

$$
P_{i}=\frac{N_{i c} \cdot P_{d} \cdot N_{s}}{N_{c} \cdot \sum\left(N_{i c} \cdot P_{d}\right)}
$$

where $N_{i c}$ is the total number of ignitions in the road class $(c), P_{d}$ is the distance-from-road probability (see Table 1), $N_{s}$ is the mean number of ignitions per bushfire season, and $N_{c}$ is the total number of cells in the road class. Table 2 lists the resulting probability of ignition for each road class and distance bin used.

Table 2. Probability of ignition for each road class and distance bin used, derived from observed frequencies of historical data

\begin{tabular}{ccr}
\hline Road class & Distance bin $(\mathrm{m})$ & $P_{i} \times 10^{3}$ \\
\hline & $0-50$ & 50.944 \\
1 & $50-100$ & 11.668 \\
& $100-150$ & 4.480 \\
& $150-200$ & 1.042 \\
\hline & $0-50$ & 7.418 \\
2 & $50-100$ & 2.177 \\
& $100-150$ & 0.886 \\
& $150-200$ & 0.271 \\
\hline & $0-50$ & 0.439 \\
3 & $50-100$ & 0.150 \\
& $100-150$ & 0.068 \\
& $150-200$ & 0.057 \\
\hline 0 & $>200$ & 0.057 \\
\hline
\end{tabular}

The conditional probability given ignition $\left(P_{T}\right)$ can be calculated by setting $N_{s}$ to unity in Eqn. 5 , thus assuming that an ignition will occur in the study area; $P_{T}$ is the chance it will occur in a given cell. By dividing $P_{i}$ by the number of days in a fire season (in this case 183), the probability of ignition for a given day can then be determined.

The model was validated by comparing the estimated $P_{T}$ values with the 2005-06 fire incident dataset containing 727 ignitions (100-m resolution) which was later incorporated into the model (Figure 1). Statistical analysis produced an $\mathrm{R}^{2}$ value of 0.845 and a standard error of 11 ignitions, suggesting that historical occurrence and human accessibility are major factors in the prediction of bushfire ignition, and thus supporting the modelling procedure used. This conclusion was subsequently checked using 
data from the following two fire seasons, which experienced a similar number of ignitions per season (757 and 736), resulting in an $\mathrm{R}^{2}$ value of 0.82 and a standard error of 13 ignitions. It must be stated that because the ignition layer is derived from historical ignitions, it does not claim to predict accurately fires started with malicious intent. The model was deemed sufficient for the purposes of this study, although it is recognised that a higher number of road classes and smaller distance bins could improve the goodness of fit.

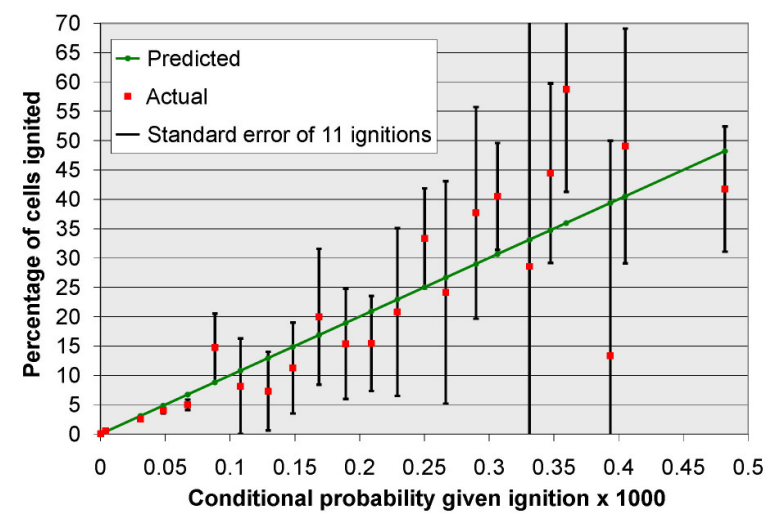

Figure 1. Percentage of cells ignited $v$. conditional probability given ignition for the 2005-06 fire incident dataset

\section{Probability of spread}

As stated earlier, the probability of spread is a conditional probability based on the probability of firepromoting weather conditions and the probability that on that day, the ignition will spread to the urban interface (based on climatic conditions, fuel load and topography).

\section{Fire weather}

In order to define representative weather conditions, the assumption was made to only consider days that have a maximum fire danger rating (FDR) of 'high' or above, corresponding to a Forest Fire Danger Index (FFDI) greater than 12 (McArthur 1967; Noble et al. 1980). This is the value where fires will freely grow and suppression by hand-crews becomes difficult. Also, prescribed burning is generally no longer permitted owing to the risk of the fire becoming unmanageable (TFS 2006). Bally (1995) found that the higher end of the 'high' rating (FFDI 18-23) resulted in almost six times more area burnt per day than the lower half (FFDI 12-17). Due to these findings, a decision was made to only include days with an FFDI of 16 or greater in this study.

Maximum FFDI measurements for each day from 1960 to 2005 were obtained from the Bureau of Meteorology. The data indicated that on average $\sim 18.5$ days per fire season $(\sim 10 \%)$ were recorded as having an FFDI of 16 or higher.

The conditions were assessed based on the wind direction and the FFDI, because wind direction highly influences the direction of spread and the FFDI is directly proportional to the rate of spread. Smith (1998) identified the distribution of fire weather days for each FFDI class based on the wind direction for the Hobart area (Table 3). Using this distribution of data, seven types of fire weather were chosen and, by applying meteorological data, the frequency of occurrence was determined for each FFDI class (Table 4). For each of the fire weather types, representative observations, i.e. temperature, relative humidity $(\mathrm{RH})$, drought factor $(\mathrm{DF})$, wind speed and wind direction were selected from the data (Table 5). These conditions are actual observations, representative of each of the selected classes, and were used in the implementation of the fire spread model.

Table 3. Percentage of wind directions for each Forest Fire Danger Index class, empty cells indicating unusual conditions (adapted from Smith 1998)

\begin{tabular}{lcccc}
\hline Wind & \multicolumn{5}{c}{ Forest Fire Danger Index } \\
direction & $16-24$ & $24-38$ & $38-60$ & $>60$ \\
\hline SE & $21 \%$ & $12.5 \%$ & & \\
SW & $19 \%$ & & & \\
N-NW & $55 \%$ & $80 \%$ & $100 \%$ & $100 \%$ \\
\hline
\end{tabular}


Table 4. Average number of days per fire season for each wind direction and Forest Fire Danger Index class, empty cells indicating unusual conditions

\begin{tabular}{lrccc}
\hline Wind & \multicolumn{5}{c}{ Forest Fire Danger Index } \\
direction & $16-24$ & $24-38$ & $38-60$ & $>60$ \\
\hline SE & 2.60 & 0.54 & & \\
SW & 2.35 & & & \\
N-NW & 6.80 & 3.48 & 1.52 & 0.20 \\
Total & 11.75 & 4.02 & 1.52 & 0.20 \\
\hline
\end{tabular}

Table 5. Representative observations for each fire weather type

\begin{tabular}{|c|c|c|c|c|c|c|}
\hline $\begin{array}{l}\text { Wind direction } \\
\text { class }\end{array}$ & $\begin{array}{l}\text { FFDI } \\
\text { class }\end{array}$ & $\begin{array}{c}\text { Temp. } \\
\left({ }^{\circ} \mathrm{C}\right)\end{array}$ & $\begin{array}{l}\mathrm{RH} \\
(\%)\end{array}$ & DF & $\begin{array}{c}\text { Wind speed } \\
\left(\mathrm{km} \mathrm{h}^{-1}\right)\end{array}$ & $\begin{array}{c}\text { Wind direction } \\
\left({ }^{\circ}\right)\end{array}$ \\
\hline \multirow{4}{*}{$\mathrm{N}-\mathrm{NW}$} & $16-24$ & 22 & 25 & 9 & 24 & 320 \\
\hline & $24-38$ & 34 & 20 & 9 & 24 & 330 \\
\hline & $38-60$ & 30 & 19 & 9 & 28 & 320 \\
\hline & $>60$ & 36 & 15 & 10 & 43 & 315 \\
\hline \multirow{2}{*}{ SE } & $16-24$ & 36 & 29 & 10 & 15 & 110 \\
\hline & $24-38$ & 35 & 25 & 9 & 24 & 115 \\
\hline SW & $16-24$ & 20 & 28 & 9 & 30 & 220 \\
\hline
\end{tabular}

\section{Mapping fire weather parameters}

Climate parameters vary spatially and temporally, and in order to investigate bushfire risk, these measures need to be mapped. The approach taken is to estimate the fire weather parameters (temperature, RH, wind speed and direction, and DF) for the entire study area, using the measurements of the Hobart Regional Forecasting Centre (HRFC). This was decided as the most appropriate approach owing to data availability for the HRFC site, its geographical location and the limited extent of the study area.

A temperature lapse rate of $0.751^{\circ} \mathrm{C}$ per $100 \mathrm{~m}$ (Nunez and Colhoun 1986) was used to map the temperature based on elevation and the HRFC-recorded temperature at an elevation of $50.5 \mathrm{~m}$. Relative humidity was mapped in a similar manner using a dewpoint lapse rate of $0.2^{\circ} \mathrm{C}$ per $100 \mathrm{~m}$ (Aguado and Burt 2004), assuming that for a day with an FFDI of greater than 38 the lower atmosphere is fully mixed to approximately $1000 \mathrm{~m}$ and the lapse rate is therefore not applied (Bally 1995).

A GIS-based wind simulation model, developed at the University of Tasmania, was used for each of the seven representative conditions listed in Table 5 in order to derive wind speed and wind direction maps for each condition. The model output contains wind speed and direction for each raster cell in a DEM of 25-m resolution based on topographical variations (slope, aspect, and convexity). As the drought factor is a regional scale estimate, the value at HRFC (9 or 10 in this case) was used for the entire study region (Tolhurst and Cheney 1999).

\section{Modelling fuel loads}

Fine fuel ( $<6 \mathrm{~mm}$ in diameter) loads in a forest are dependent on the rate of litter production and the decomposition rate of the litter. In this study, the vegetation was classified based on the dominant species identified by Smith (1998):

1. Allocasuarina verticillata forest or woodland (Ave)

2. Eucalyptus amygdalina forest (Eamh)

3. Eucalyptus globulus and Eucalyptus viminalis forest (Egv)

4. Eucalyptus pulchella forest (Epu)

5. Grassy woodland (Gw)

6. Eucalyptus tenuiramis heathy forest (Hft)

7. Broadleaved wet forest (Wfb)

8. Eucalyptus delegatensis (Ede)

9. Agricultural land

10. Native grass

11. Heathland. 
In Australia, the Olson (1963) model has been adopted as the basis of many fuel accumulation models (e.g. Birk and Simpson 1980; Marsden-Smedley and Catchpole 1995; Mercer et al. 1995; Brandis and Jacobson 2003). The model assumes litter is produced at a constant rate and that decomposition rates are dependent on the amount of fuel (Bresnehan 1998):

$$
F L=y_{\max } \cdot\left(1-e^{\left(-k_{1} \cdot t\right)}\right)+y_{r} \cdot e^{\left(-k_{2} \cdot t\right)}
$$

where $F L$ is the total fuel load $\left(\mathrm{t} \mathrm{ha}^{-1}\right), y_{\max }$ is the steady-state fuel load $\left(\mathrm{t} \mathrm{ha}^{-1}\right), y_{r}$ is the residual fuel load after the last fire $\left(\mathrm{t} \mathrm{ha}^{-1}\right), k_{1}$ and $k_{2}$ are the decomposition constants for accumulating and residual fuel respectively, and $t$ is the time since the last fire (years). Table 6 shows the model parameters used for each fuel type considered.

A layer consisting of the time since the last fire occurred (in years) was produced. As a complete fire history did not exist for the study area and to give the study longevity, a constant of 15 years since the last fire was adopted. In order to determine the present risk posed by bushfire, a more accurate fire history is required that can then be converted to a more appropriate fuel load estimate using Eqn. 6 in conjunction with the parameters in Table 6 . Here, the value of 15 years was chosen because most fuels reach $90 \%$ of the maximum fuel load in this time-span and it is recognised as a realistic time interval, although most dry eucalypt forests in the area usually burn within a 10-year period (Smith 1998). It should be noted that Eamh does not produce a quasi-steady fuel load after a certain number of years but rather keeps accumulating fuel by a relatively steady amount.

Table 6. Olson model parameters used for each fuel type considered

\begin{tabular}{crcccl}
\hline Fuel type & $y_{\max }\left(\mathrm{t} \mathrm{ha}^{-1}\right)$ & \multicolumn{1}{c}{$k_{1}$} & $y_{r}\left(\mathrm{t} \mathrm{ha}^{-1}\right)$ & \multicolumn{1}{c}{$k_{2}$} & \multicolumn{1}{c}{ Source } \\
\hline Ave & 12.105 & 0.6890 & -7.982 & 0.6890 & Bresnehan (1998) \\
Eamh & 1199.500 & 0.0005 & 2.920 & 0.0103 & Bresnehan (1998) \\
Ede & 22.900 & 0.3100 & 1.920 & 0.3100 & Raison et al. (1986) \\
Egv & 28.169 & 0.0340 & 2.959 & 0.0340 & Bresnehan (1998) \\
Epu & 18.310 & 0.1140 & 1.791 & 3.1530 & Bresnehan (1998) \\
Gw & 9.810 & 0.1530 & 1.920 & 0.1530 & Fensham (1992) \\
Hft & 12.716 & 0.2620 & 1.920 & 0.2620 & Fensham (1992) \\
Wfb & 14.287 & 0.3130 & 1.920 & 0.3130 & Fensham (1992) \\
\hline
\end{tabular}

\section{Defining the urban interface}

The urban interface is defined as a line or zone that divides the vegetation from manmade structures or developments (Blanchi et al. 2004). In the present study, it was identified as those vegetation cells immediately bordering cells classified as 'urban', based on the TASVEG 2005 dataset. TVMP (2005) states the positional accuracy of this dataset as $17.5 \mathrm{~m}$. However, because it has been produced from aerial photography that is up to 17 years old, the uncertainty is expected to be higher in recently developed suburbs. It should be noted that all datasets with a higher resolution than 30 by $30 \mathrm{~m}$ were resized to this cell size in order to enable a consistent analysis.

\section{Implementation of the bushfire simulation system}

The majority of existing bushfire simulation systems are operationally focused and inflexible in nature; thus they do not meet the specific needs of the risk assessment process (as defined in this study). The method presented in this paper relies on the simulation system being executed hundreds of thousands of times, and the relatively large run times of existing models make this impractical. It should be noted that, although it is recognised that the presentation of the model output is an important aspect for fire managers, this study focused on the probability of a fire reaching the urban interface and the fire's intensity, rather than the visualisation of the fire front at given time intervals. A simulation system was created specifically for use within the framework of this study, allowing for optimisation to address these issues at a later stage. The model was implemented in the Python programming language, linked to the ArcGIS software package.

Fire behaviour characteristics are calculated using McArthur's Mark V Forest Fire Danger Meter, McArthur's Mark V Grassland Fire Danger Meter and the heathland model (Catchpole et al. 1998) for 
the different fuel types present in the Hobart area. The simulated fire growth uses a regular grid method developed by Finney (2002) based on cumulative minimum travel times. These travel times are calculated along connecting neighbouring cell centres using the rate of spread in each direction. The reason for implementing this method is that it produces an output very similar to the Huygens' principle expansion method but is almost eight times faster (Finney 2002).

This bushfire simulation system is then applied to determine the time taken for a 'fire' to spread from each ignition point to each interface point for each of the seven fire weather conditions defined earlier. The model uses the layers produced in the previous sections as well as slope and aspect layers derived from a DEM. Cumulative spreading times along with the probability of spotting (sparks and burning embers thrown ahead of the fire front) are used to determine the probability that the 'fire' will reach the urban interface.

In this case, a maximum spread time of four hours is used to determine the probability that a fire will reach the urban interface; the time period chosen is an estimation of the maximum time taken by the fire service to fully respond as well as taking into account the deterioration of the maximum fire weather conditions. As the time equates to a probability, the probability of spotting across a road or low fuel zone (based on fire intensity, wind speed and wind direction) can be related to a time by:

$$
T_{i+1}=T_{\max }\left(1-\frac{\left.\left(T_{i}+\Delta T\right) \cdot P_{s p}\right)}{T_{\max }}\right)
$$

where $T_{i}$ and $T_{i+l}$ are the cumulative minimum travel times at intervals $i$ and $i+1$ respectively, $\Delta T$ is the time taken for the fire to spread to the next cell calculated from the rate of spread and cell size, $P_{s p}$ is the probability of spotting determined using a fuzzy model based on Byram's (1959) fireline intensity, and $T_{\max }$ is the maximum spread time.

The travel time for the 'fire' to reach the urban interface is then converted to the probability $P_{U i}$ of an ignition $(i)$ reaching the urban interface (i.e. the probability of spread):

$$
P_{U i}=1-\left(\frac{T}{T_{\max }}\right)
$$

where $T$ is the time taken to spread from the ignition point to the urban interface. Note that the probability is reduced linearly such that at $4 \mathrm{~h}$ (the chosen value for $T_{\max }$ in this study) from ignition its value is zero.

According to Bradstock and Gill (2001), the combined probability of ignition in the landscape and the resultant fire reaching the urban interface is the product of the two probabilities concerned. Hence, the combined probability $P_{U i Z}$ of a fire igniting and spreading to an urban interface cell $(U)$ for a given fire weather condition $(Z)$ is given by:

$$
P_{U i Z}=\sum_{i} P_{U i} \cdot P_{i} \cdot F_{Z}
$$

where $P_{i}$ is the probability of ignition on a given day for the cell, and $F_{Z}$ is the average number of days per fire season for a fire weather condition to occur.

\section{Interface point approach}

The probability of a fire reaching the urban interface is a function of the probability of ignition of many neighbouring cells, which is determined by fire simulation. The conventional approach for model implementation is to run the simulation for each potential ignition cell to determine the probability that a fire will reach each urban interface cell.

In order to increase processing efficiency, the vector components of the model (e.g. aspect and wind direction) can be reversed, using the interface point as the 'ignition' point (Figure 2). Conventionally, if we have 2000 potential ignition points and 20 interface points, we would have to implement the simulation 2000 times. Many of these 'fires' would be deemed to have no effect on any interface point. However, by reversing the vectors and 'igniting' from the interface point, this computationally expensive simulation will only need to be run 20 times for the same result, and only the necessary fire paths and ignition points are taken into account. In reference to Figure 2, the fire spread simulation is 
implemented for each interface cell as opposed to each (white) vegetation cell. An adjustment is made for the spotting component of the simulation system such that the fire behaviour of points on the other side of a road or in low-fuel zones is incorporated, because simply reversing the spotting model will not generate valid results.

This procedure is possible because the probability of spread (i.e. the link between the ignition and interface points) is based on time, a scalar value. Applying this approach made the computations 15-20 times faster for this simulation system and this study area. Owing to its increased efficiency, this approach is very valuable for large subject areas and small cell sizes because the model is run for each interface point instead of every potential ignition cell.

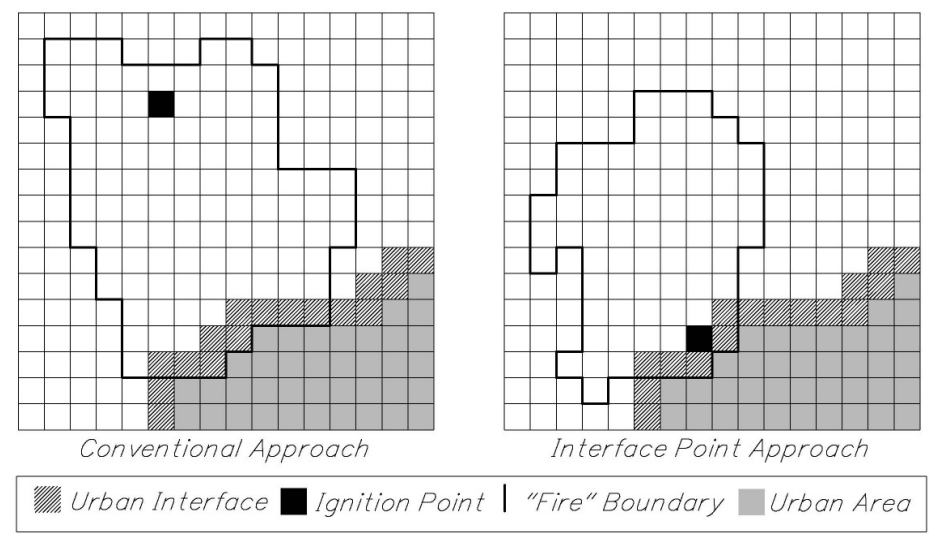

Figure 2. Graphical representation of the conventional approach to determine the probability of a fire reaching the urban interface and the more efficient interface point approach used in this study

\section{Probability of urban penetration}

The probability of urban penetration (termed $E$ in Eqn. 1) is the vital link between the probability of reaching the urban interface and the consequence component and is therefore included in the likelihood model.

The probability of urban penetration was modelled based on two components: the distance from the interface and the local wind direction. Ahern and Chladil (1999) estimated that $90 \%$ of houses were destroyed by burning ember attacks (or spotting); thus, the spotting ability of each urban interface cell was determined. Byram's fireline intensity (Byram 1959) was calculated for all urban interface cells based on the maximum rate of spread and the fuel load. It was assumed that a value of greater than 2000 $\mathrm{kW} \mathrm{m}{ }^{-1}$ would produce burning embers. For an intensity of less than this value or grassland fire behaviour, only cells immediately bordering the interface cell were attributed a probability (Shields 2004; NSW RFS 2006).

Using the findings by Ahern and Chladil (1999) and the predictions by the NSW Rural Fire Service (NSW RFS 2006), the probability based on the distance factor was derived. The maximum penetration distance was defined as $180 \mathrm{~m}$ as this captures $95 \%$ (or $2 \times$ standard deviation) of the houses destroyed by large fires (Ahern and Chladil 1999). The assumption is made that urban areas immediately bordering the interface cell will be threatened (Shields 2004).

As burning embers are carried by the wind, it was assumed that only cells in the wind direction from the interface cell are affected. Probability based on direction was calculated as the cosine of the difference between the wind direction and the bearing of the cell with respect to the interface point. The probability of urban penetration was calculated as the product of the direction based component and the distance-based component.

The final likelihood of being threatened by an uncontrollable bushfire in a given fire season is then calculated by:

$$
\text { likelihood }=\sum_{Z} P_{U i Z} \cdot P_{P Z}
$$

where $P_{U i Z}$ is the probability that a fire will ignite and spread to the interface for a given fire weather condition $(Z)$, and $P_{P Z}$ is the probability of urban penetration for a given fire weather condition. 
This likelihood component considers only the first three probabilities of Eqn. 1 and hence is the likelihood that a bushfire will threaten people and property. In order to determine the likelihood of adverse effects to people and property within the built environment, the remaining two terms in Eqn. 1 (termed $G$ and $H$ ) would also need to be included.

Figure 3 shows the model output of the likelihood component (Eqn. 10) for part of the study area. Note the reduction in probability with distance from the urban interface, which is defined by the outmost pixels shown in the overlay, bordering on the forested area.

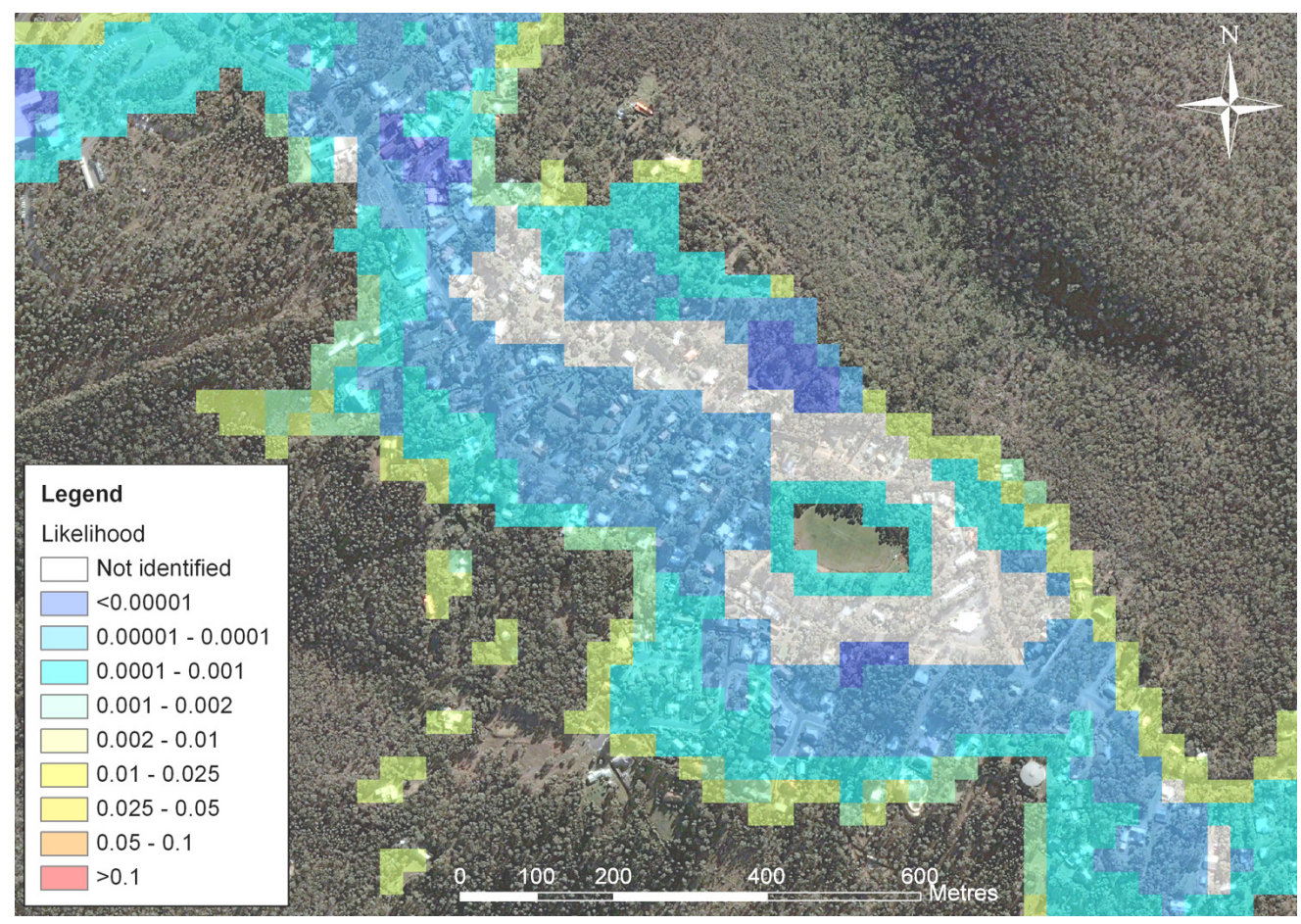

Figure 3. Detailed view showing the likelihood of being threatened by an uncontrollable bushfire in a given fire season. The image shown is a part of the Mount Nelson suburb, Hobart, acquired by the Quickbird satellite.

\section{Uncertainty assessment of the likelihood}

In a GIS project, the uncertainty of the output is always related to the uncertainty of the input ('garbage in, garbage out' principle). The output maps are only 'pretty pictures' and of little use unless an uncertainty assessment is carried out. The uncertainty of the output in relation to the input errors can be calculated by applying the first-order Taylor series method to the equations used (Bachmann and Allgower 2002). The uncertainties adopted for the assessment in our case study are shown in Table 7.

Table 7. Uncertainty and justification for each input variable used in the uncertainty analysis

\begin{tabular}{lcl}
\hline Input variable & Uncertainty & \multicolumn{1}{c}{ Justification for uncertainty estimate } \\
\hline Drought factor & \pm 0.5 & Regional scale estimate, given as an integer number \\
Wind speed $\left(\mathrm{km} \mathrm{h}^{-1}\right)$ & \pm 10 & Use of a basic model and natural variations \\
Wind direction $\left(^{\circ}\right)$ & \pm 20 & Use of a basic model and natural variations \\
Slope $\left({ }^{\circ}\right)$ & \pm 3 & Slope layer is resized to $30 \mathrm{~m}$ from 1 m contours \\
Aspect $\left({ }^{\circ}\right)$ & \pm 10 & Aspect layer is resized to 30 m from 1 m contours \\
Relative humidity $(\%)$ & \pm 2 & Local area elevation effects are modelled \\
Fuel load $\left(\mathrm{t} \mathrm{ha}^{-1}\right)$ & forest: \pm 2 & Model analysis, variations in transition zones \\
Temperature $\left({ }^{\circ} \mathrm{C}\right)$ & grassland: \pm 0.5 & Local area elevation effects are modelled \\
Ignition probability $P_{i}$ & \pm 2 & Analysis of ignition model \\
\hline
\end{tabular}

Applying these values to representative conditions reveals that the main contributors to the uncertainty in the rate of spread for forest fires are wind speed (40\%), slope (30\%) and fuel load (20\%). In the grassland model, wind speed accounts for the majority of the error $(65 \%)$, while slope contributes $17 \%$. This is consistent with the findings of Bachmann and Allgower (2002) and Jones et al. (2004). 
The uncertainty of the input variables has a significant impact on the resulting errors in fire behaviour modelling (Bachmann and Allgower 2002). Therefore, these uncertainties were considered in relation to their effect on the entire calculation of likelihood by applying the Taylor series method of uncertainty propagation to 100 randomly selected points from the likelihood layer. The average relative error for the likelihood was $\pm 40 \%$, although large variability existed (standard deviation of $\pm 18 \%$ ), showing that a reduction in the uncertainty of the input variables will greatly improve the reliability of this study. As expected, the model is highly influenced by the ignition layer, suggesting that this layer requires more attention in order to achieve a consistently good result. In the probability of spread model, it is apparent that the greater the 'travel time' and the distance covered, the larger the resulting uncertainty. In cases of spread over $8 \mathrm{~km}$ an error of around $\pm 100 \%$ was obtained, clearly showing that the uncertainty in the input variables has an enormous effect over large distances. Therefore, for implementation in areas larger than this case study and spread longer than $4 \mathrm{~h}$, the input variables will need significant attention, in particular the DEM and wind model.

Considering the assumptions made and that inherent uncertainty exists in the fire behaviour model, the resultant variance in the likelihood is described as the standard deviation of the 'best prediction' as a result of the input uncertainties propagating through the study.

The model output shown in Figure 3 can be accepted as a realistic result. A validation with an independent dataset containing 30 years of historical fire boundaries for the Wellington Park management area illustrates that our method discriminates high- and low-risk areas well for high fire weather conditions. As, in this case, most ignitions occur near roads (see Table 1), the results were compared to using a simple distance function (SDF) generated by replacing our spread model with a normalised probability function based on the distance from each ignition point. Given the same ignition model, our spread model produces a substantially better discrimination between high and low likelihood classes, as evident from a range of $70 \% v$. a range of $30 \%$ (Table 8 ).

In Table 8, the 'actual' columns show the percentage of those cells identified by the model used and the SDF as belonging to the given likelihood bin (Eqn. 10) that were actually affected by fire. The 'predicted' column is the expected percentage based on the likelihood and 30 years of data. For example, over 30 years at a likelihood of 1 in $<40$ years, we would expect $>75 \%$ of these cells to be affected by fire. Of the cells identified by the model used and the SDF as having this likelihood, 93.2 and $71.8 \%$ were actually affected by fire in the period 1973-2003 respectively.

It is important to note that, owing to a lack of information about the Wellington Park dataset, the magnitude of the likelihood could not be assessed as many of the historical fire boundaries resulted from non-threatening fires on low fire weather days that were left to burn to the interface before being extinguished. It should be noted that our model specifically concentrates on dangerous fire weather conditions and does not account for FFDIs less than 16, a fact that contributes greatly to the underprediction for low likelihoods apparent in Table 8.

Table 8. Percentage of urban interface cells actually affected by bushfire from 1973 to 2003 with respect to the predictions of our model and the SDF (simple distance function)

\begin{tabular}{lccc}
\hline Likelihood & \multicolumn{3}{c}{ Percentage affected by bushfire 1973-2003 } \\
1 in & Predicted & Actual (Model) & Actual (SDF) \\
\hline $1000-10000$ & $0.3-3$ & 22.6 & 41.6 \\
$500-1000$ & $3-6$ & 25.5 & 34.9 \\
$100-500$ & $6-30$ & 41.9 & 37.3 \\
$40-100$ & $30-75$ & 59.1 & 44.8 \\
$<40$ & $>75$ & 93.2 & 71.8 \\
\hline
\end{tabular}

\section{Consequence and risk}

Consequence

The consequence component in Eqn. 2, representing the impact of a fire starting and spreading, can be social, economic, political or environmental (Shields 2004). The present study concentrates on the potential impact on urban residences (buildings) as this is easily defined and the most readily recognised impact resulting from a bushfire. In this case, the consequence component is based on dwelling density, i.e. the larger the number of dwellings in a region, the greater the impact an 
uncontrollable bushfire will have. However, with more data available, a scaled value based on, e.g., demographic, commercial, economic and historical values could be easily implemented.

The Tasmania Fire Service address point dataset from 2005 was used to determine dwelling density for the urban areas. These address points are defined as the centroids of the Tasmanian Department of Primary Industries and Water (DPIW) cadastre dataset. Owing to the uncertainty involved in the identification of the urban interface and the fact that the address point marks the centre of the cadastral boundaries as opposed to the actual building, it was decided to utilise the average dwelling density of the neighbouring cells for each cell designated 'urban'. This resulted in a smoothing effect that is not as dependent on the exact position of the address point as using the sum of the cells based on the spatial location. The final layer uses the number of dwellings per 0.09 ha $(30 \times 30 \mathrm{~m})$, which equates to 'virtual' dwellings present in each cell.

\section{Risk}

In order to allow for risk decision making, a risk index is defined based on Eqn. 2, where likelihood represents the linked probabilities of ignition, spread and urban penetration (see Eqn. 3), while consequence is the number of dwellings present in a certain cell (Figure 4).

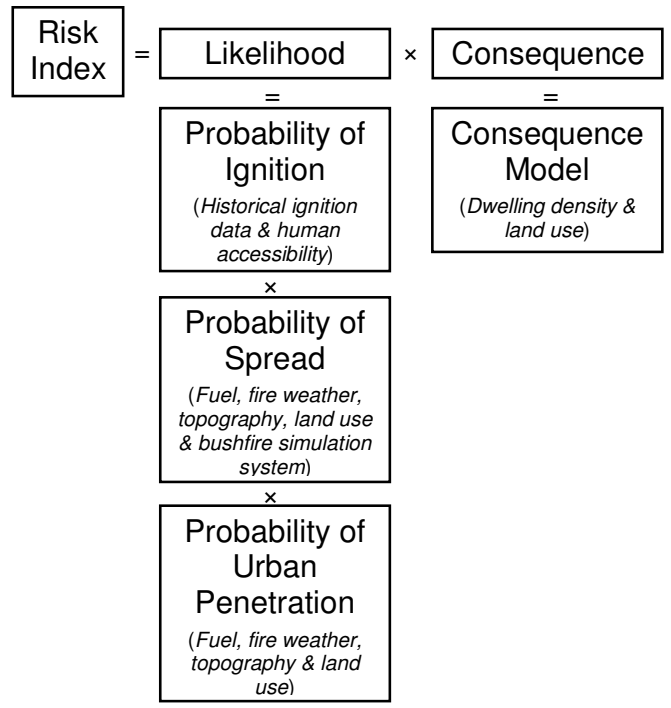

Figure 4. Graphical interpretation of the approach used to calculate the risk index

This risk index is the value on which the decision is based to either accept or treat the risk. For example, if the likelihood of a cell being threatened by bushfire is 0.01 and there are two dwellings represented by this cell, then the risk index is 0.02 and therefore twice as large, given that it can result in twice the consequence. By assuming a threshold of acceptable risk, e.g. 0.01, suggesting a risk of 1 in 100 that a dwelling will be threatened by bushfire, areas with a greater risk than this threshold can be treated whereas a lower risk may be accepted in other areas. Treatment of the risk may include increasing resources to the brigades responsible for these areas or fuel reduction burns and increasing community awareness in these areas.

\section{Conclusions}

This study has developed an effective method for the implementation of the bushfire risk framework introduced by Shields and Tolhurst (2003) and later refined by Shields (2004), using available spatiotemporal data. The greater Hobart area, Tasmania, was used as an example to show the effectiveness of the method for local- to regional-scale areas. The spatial extent and quantification of the bushfire risk in the Hobart area were successfully identified. The interface point approach has been shown to increase processing efficiency by up to 20 times, potentially enabling the model to be run in near-real-time in order to aid fire management.

This assessment for the Hobart area may be used as a first-pass estimation in the bushfire riskmanagement process. Further refinements to the method as well as improvements in regards to the input datasets will result in an optimisation of this model. 
Fires igniting outside but spreading into the study area could be accommodated by analysis of the surrounding areas and a subsequent update of the boundary cells, while parameters can be changed to allow for fires that burn over several days. As the fire spread model is highly dependent on the input data, in particular wind direction and speed, the introduction of a more comprehensive wind model would reduce the uncertainty associated with the current model. This could be achieved by analysing weather observations over a fire season for many stations located throughout the study area. These observations could also be used to determine a method of modelling DF variation at the local scale using, for example, solar radiation, rainfall, soil, interception and run-off.

The risk model output is highly dependent on the definition of the urban interface and could therefore be improved by a reclassification of the interface using currently available satellite images. A building location dataset could serve this purpose and also help inform the consequence model. As a complete fire history did not exist for the study area, a current bushfire risk cannot be produced for this case study. Instead, the resulting risk is a longer-term result identifying the areas that are most susceptible to the risk posed by bushfire in the absence of fuel-reduction strategies, i.e. the areas that require low fuel levels to be maintained. In order to support future planning of prescribed burns, a fire history must be developed or, alternatively, a fuel load survey must be carried out and integrated into the model.

This study has provided a template for future studies to be conducted. We have resolved many of the implementation issues involved with dynamic risk modelling, such as increasing processing efficiency and quantifying probabilities and uncertainties using historical data through the creation of a riskspecific bushfire simulation system, the interface point approach and a spatiotemporal algorithm to estimate spread probabilities. We have defined a method for modelling ignition probabilities using representative conditions in order to manage large fire weather datasets. With the modifications outlined above, the model has the potential to be used as a reliable near-real-time tool for assisting fire management decision making with regards to the risk posed by bushfire, such as allocation of resources, fuel reduction burn planning and mapping, strategic placement of law enforcement on high fire weather days, identification of areas requiring increased community education, town planning, and firefighter training.

\section{Acknowledgements}

We thank the Tasmania Fire Service, the Bureau of Meteorology (Tasmania Antarctica Region), the Department of Primary Industries and Water and the University of Tasmania for their contribution in providing datasets.

\section{References}

Aguado E, Burt JE (2004) 'Understanding weather and climate.' (Pearson Education: Upper Saddle River, NJ)

Ahern A, Chladil M (1999) How far do bushfires penetrate urban areas? In 'Proceedings of the 1999 Australian Disaster Conference', 1-3 November, Canberra, ACT. pp. 21-26. (Emergency Management of Australia: Canberra, ACT)

AS/NZS (2004) 'Risk management. Australian/New Zealand Standard AS/NZS 4360:2004.' (Standards Australia: Sydney)

Bachmann A, Allgower B (2002) Uncertainty propagation in wildland fire behaviour modelling. International Journal of Geographical Information Science 16, 115-127. doi:10.1080/ 13658810110099080

Bally J (1995) The Haines index as a predictor of fire activity in Tasmania. In 'Bushfire '95: Presented papers. Australian Bushfire Conference, 27-30 September, Hobart'. (Forestry Tasmania, Parks \& Wildlife Service and Tasmania Fire Service: Hobart, TAS)

Berjak SG, Hearne JW (2002) An improved cellular automaton model for simulating fire in a spatially heterogeneous Savanna system. Ecological Modelling 148, 133-151. doi:10.1016/S03043800(01)00423-9

Birk EM, Simpson RW (1980) Steady state and the continuous input model of litter accumulation and decomposition in Australian eucalypt forests. Ecology 61, 481-485. doi:10.2307/1937411

Blanchi R, Leonard J, Maughan D (2004) Towards new information tools for understanding bushfire risk at the urban interface. In 'Online proceedings of Bushfire 2004, Australian Bushfire Conference', 
25-28 May, Adelaide, SA. Available at http://www.bushfirecrc.com/research/downloads/Bushfireadelaide-2004-blanchi1.pdf [Verified 2 June 2009]

Bradstock RA, Gill AM (2001) Living with fire and biodiversity at the urban edge: in search of a sustainable solution to the human protection problem in southern Australia. Journal of Mediterranean Ecology 2, 179-195.

Brandis K, Jacobson C (2003) Estimation of vegetative fuel loads using Landsat TM imagery in New South Wales, Australia. International Journal of Wildland Fire 12, 185-194. doi:10.1071/WF03032

Bresnehan SJ (1998) 'An Assessment of Fuel Characteristics and Fuel Loads in Dry Sclerophyll Forests in South-East Tasmania.' (Tasmanian Forest Research Council: Hobart, TAS)

Byram GM (1959) Forest fire behavior. In 'Forest Fire: Control and Use'. (Ed. KP Davis) pp. 90-123. (McGraw-Hill: New York)

Catchpole WR, Bradstock RA, Choate J, Fogarty LG, Gellie N, McCarthy GJ, McCaw WL, MarsdenSmedley JB, Pearce G (1998) Cooperative development of equations for heathland fire behaviour. In 'Proceedings of 3rd International Conference of Forest Fire Research and 14th Fire and Forest Meteorology Conference'. 16-20 November, Luso, Portugal, pp. 631-645. (University of Coimbra: Coimbra)

Fensham RJ (1992) The management implications of fine fuel dynamics in bushlands surrounding Hobart, Tasmania. Journal of Environmental Management 36, 301-320. doi:10.1016/S03014797(08)80004-7

Finney MA (2002) Fire growth using minimum travel time methods. Canadian Journal of Forest Research 32, 1420-1424. doi:10.1139/X02-068

Garvey M (1996) The use of geographic information systems to analyse wildfire threat. In 'Proceedings of Fire and Biodiversity: the Effects and Effectiveness of Fire Management', 8-9 October 1994, Melbourne. pp. 219-226. (Department of Environment, Sport and Territories: Canberra, ACT)

Genton MG, Butry DT, Gumpertz ML, Prestemon JP (2006) Spatiotemporal analysis of wildfire ignitions in the St Johns River Water Management District, Florida. International Journal of Wildland Fire 15, 87-97. doi:10.1071/WF04034

Jones SD, Garvey MF, Hunter GJ (2004) Where's the fire? Quantifying uncertainty in a wildfire threat model. International Journal of Wildland Fire 13, 17-25. doi:10.1071/WF02050

Knight I, Coleman J (1993) A fire perimeter expansion algorithm based on Huygen's wavelet propagation. International Journal of Wildland Fire 3, 73-84. doi:10.1071/WF9930073

Luke RH, McArthur AG (1978) 'Bushfires in Australia.' (Australian Government Publishing Service: Canberra, ACT)

Malcolm I, Smith K, Oh T, Collins N (1995) Wildfire threat analysis. In 'Bushfire '95: Presented Papers. Australian Bushfire Conference, 27-30 September, Hobart'. (Forestry Tasmania, Parks \& Wildlife Service and Tasmania Fire Service: Hobart, TAS)

Marsden-Smedley JB, Catchpole WR (1995) Fire behaviour modelling in Tasmanian buttongrass moorlands I. Fuel characteristics. International Journal of Wildland Fire 5, 203-214. doi:10.1071/WF9950203

McArthur AG (1967) Fire behaviour in eucalypt forest. Commonwealth of Australia Forestry and Timber Bureau, Leaflet 107, p. 25.

McRae RHD (1992) Prediction of areas prone to lightning ignition. International Journal of Wildland Fire 2, 123-130. doi:10.1071/WF9920123

Mercer GN, Gill AM, Weber RO (1995) A flexible, non-deterministic, litter accumulation model. In 'Bushfire '95: Presented Papers. Australian Bushfire Conference, 27-30 September, Hobart'. (Forestry Tasmania, Parks \& Wildlife Service and Tasmania Fire Service: Hobart, TAS)

Noble IR, Bary GAV, Gill AM (1980) McArthur's fire-danger meters expressed as equations. Australian Journal of Ecology 5, 201-203. doi:10.1111/J.1442-9993.1980.TB01243.X

NSW RFS (2006) 'Planning for Bushfire Protection.' (NSW Rural Fire Service: Sydney)

Nunez M, Colhoun EA (1986) A note on air temperature lapse rates on Mount Wellington, Tasmania. Papers and Proceedings of the Royal Society of Tasmania 120, 11-15.

NZ NRFA (2005) 'New Zealand Wildfire Threat Analysis Workbook.' (National Rural Fire Authority: Wellington)

Olson JS (1963) Energy storage and the balance of producers and decomposers in ecological systems. Ecology 44, 322-331. doi:10.2307/1932179 
Preisler HK, Brillinger DR, Burgan RE, Benoit JW (2004) Probability-based models for estimation of wildfire risk. International Journal of Wildland Fire 13, 133-142. doi:10.1071/WF02061

Raison RJ, Woods PV, Khanna PK (1986) Decomposition and accumulation of litter after fire in subalpine eucalypt forests. Australian Journal of Ecology 11, 9-19. doi:10.1111/J.14429993.1986.TB00913.X

Ripley BD (1976) The second-order analysis of stationary point processes. Journal of Applied Probability 13, 255-266. doi: $10.2307 / 3212829$

Shields BJ (2004) State of knowledge: bushfire risk management. Report to the Department of Urban Services, Canberra.

Shields BJ, Tolhurst KG (2003) A theoretical framework for wildfire risk assessment. In 'Proceedings of 3rd International Wildland Fire Conference and 10th Annual AFAC Conference', 3-6 October, Sydney, Australia.

Smith D (1998) Mapping the bushfire danger of Hobart. GradDip (Environmental Studies) (Hons) thesis, University of Tasmania, Australia.

TFS (2006) 'Interim Guidelines for Burning Vegetation.' (Tasmania Fire Service: Hobart, TAS)

Tolhurst KG, Cheney NP (1999) 'Synopsis of the Knowledge Used in Prescribed Burning in Victoria.' (Department of Natural Resources and Environment: Melbourne, VIC)

TVMP (2005) Tasmanian Vegetation Mapping Program metadata: TASVEG version 1.0. (Department of Primary Industries and Water: Hobart, TAS)

Wilson A (1998) Fire planning support tool. Report to the Department of Natural Resources and Environment, Victoria.

Author Posting. (C) International Association of Wildland Fire, 2010.

This is the authors' version of the work. The definitive version was published in the International Journal of Wildland Fire, Volume 19, Number 5, August 2010, pp. 649-658. 